\title{
On the relation between public debt and economic growth: An empirical investigation
}

\author{
Bettina Bökemeier* • Alfred Greiner \\ Department of Business Administration and Economics, Bielefeld University, Germany
}

Received: 17 March 2015

Revised: 8 July 2015

Accepted: 9 July 2015

\begin{abstract}
In this paper we empirically study the relation between public debt and economic growth. We analyze how the public debt to GDP ratio at a certain point in time is cor- related with the GDP growth rate in the following period, where we consider a one-year time span, a three-year time interval and a five-years interval. Using panel data compris- ing seven developed countries from 1970-2012, we estimate a pooled regression model and a random effects model. We find some evidence for a significantly negative relation between debt and growth. Further, for most specifications this relationship does not seem to be characterized by non-linearities.
\end{abstract}

Keywords: public debt, economic growth, empirics

JEL Classification Codes: E62, H63

\section{Introduction}

The financial crisis that had started as a sub-prime crisis in the USA in 2008 turned into a public debt crisis, particularly in some European economies. Since banks had to be backed by governments in order to prevent a break-down of the banking sector, public debt relative to GDP increased dramatically. Especially, Ireland as well as some Southern European countries, that had accumulated a huge amount of public debt relative to GDP already before the outbreak of the crisis, got into severe trouble. This evolution has renewed the economic research dealing with the question of how public debt can affect the real side of market economies.

With this paper we also intend to contribute to the empirical research dealing with the question of how public debt and economic growth are related. We perform panel data estimation

\footnotetext{
* Corresponding author. E-mail: bboekemeier@wiwi.uni-bielefeld.de.

Citation: Bökemeier, B. and Greiner, A. (2015) On the relation between public debt and economic growth: An empirical investigation, Economics and Business Letters, 4(4), 137-150.
} 
with selected euro zone economies and the USA. Our estimations yield empirical evidence for a significantly negative relationship between the debt to GDP ratio and economic growth in subsequent periods. Further, we only find very weak evidence that this relationship is characterized by non-linearities.

Thus, the correlation between public debt, on the one hand, and economic growth, on the other hand, has been the subject of a great many studies in the recent past. A frequently cited contribution is the one by Reinhart und Rogoff (2010) who, using histograms, find an inverted U-shaped relation between debt and growth, with the relationship becoming negative once the debt to GDP ratio exceeds about 90 percent $^{1}$. Although that paper seems to contain a spreadsheet coding error that led to a miscalculation of the growth rates of some economies, there are other studies that also detect an inverted U-shaped relation between debt and growth.

For example, Caner et al. (2010) analyze 101 countries over the time period 1980-2008 and detect a critical value for the debt ratio beyond which the relation between debt and growth becomes negative. The threshold of the debt to GDP ratio is about 77 percent and it depends on which countries are included in their sample.

Another contribution within that line of research has been presented by Checherita and Rother (2010). Those authors perform regression analyses for 12 euro area countries over the period 1970-2011, where they distinguish between annual growth rates and growth rates over a time span of 5 years. For both cases, these authors also find an inverted U-shaped relation between debt and growth, with the threshold of public debt being at 70-80 percent of GDP. In addition, Checherita-Westphal et al. (2012) estimate regressions for various subsamples of OECD countries and find values for the threshold of the debt to GDP ratio that range between

43 and 63 percent of GDP ${ }^{2}$. Egert (2015) extends the time period of the sample in Reinhart and Rogoff back to 1790 and detects a small negative correlation between debt and growth. Using an endogenous threshold model, he finds some evidence of a non-linear relationship between debt and growth. Further, Egert (2015) points out that both the presence and the level of the thresholds are not robust to small changes in country coverage, data frequency and to changes in the assumptions on the minimum number of observations included in each regime. Dreger and Reimers (2013) study the effect of the debt ratio on the real GDP per capita growth rate for two groups of countries, euro-zone members and non-euro-zone European economies, and further separate the situations in sustainable and non-sustainable debt states. They utilize a pooled panel regression and also find a negative effect of the debt ratio on economic growth.

On the other hand, there exist empirical studies that only find a negative correlation between the debt to GDP ratio and economic growth. Ferreira (2009), for example, performs Granger causality tests for 20 OECD countries over the time period from 1988-2001, where he studies annual growth rates. It turns out that higher debt to GDP ratios exert a negative effect on the growth rates of economies. This effect is statistically significant and it goes in both directions, that is higher public debt reduces economic growth and less growth implies higher government debt. Kumar and Woo (2010) analyze 19 countries over the time span from 1970-2007, where they estimate growth regressions with the growth rate over 5 years as the dependent variable. The result of their estimations is a definitely negative relationship between the debt to GDP ratio at the beginning of a period and the growth rate of that period. In addition, they investigate the relation between public deficits and economic growth and detect a negative correlation, too.

\footnotetext{
${ }^{1}$ Earlier studies using time series data for the USA find a growth maximizing debt to GDP ratio of about 40 to 50 percent, cf. Smyth and Hsing (1995) and the literature cited in that paper.

${ }^{2}$ However, within a theoretical endogenous growth model, one needs extreme assumptions to get an inverse Ushaped relation between debt and growth (cf. Greiner, 2013).
} 
Their study also reveals non-linearities such that higher public deficits and higher debt to GDP ratios go along with disproportionately negative growth rates. Ballasone et al. (2011) analyze the relation between the ratio of public debt relative to GDP and the growth rate of real per capita income in Italy over the period 1861-2009. They detect a negative correlation between government debt and economic growth, where the negative effect seems to work mainly through reduced investment.

Panizza and Presbitero (2013), finally, present a survey of papers dealing with debt and growth. They find that the presence of thresholds and, more generally, of a non-monotonic relationship between public debt and economic growth is neither robust to changes in data coverage nor to the empirical techniques resorted to. They maintain that empirical studies dealing with that subject should, in particular, put a strong emphasis on cross-country heterogeneity.

The rest of the paper is organized as follows. In the next section, we first describe the estimation procedure and the data we use in our estimations. Section 3 presents the estimations results and section 4 , finally, concludes.

\section{The estimation procedure and the data}

In order to analyze how the public debt to GDP ratio at a certain point in time affects economic growth in subsequent periods, we perform panel data estimation with annual data from seven selected western countries of the euro area (Austria, France, Germany, Italy, the Netherlands, Portugal and the USA) covering the years from 1970 until 2012. The main criterion for the selection of the countries in our sample was that we intended to have economies that display similar patterns with respect to the time paths of the variables, in particular with respect to the debt to GDP ratio, (besides availability of the data) in order to reduce the degree of heterogeneity in the sample. All those countries are developed economies and display similar patterns with respect to the time series of public debt and economic growth. With six European economies the focus is set on this region, where Germany and France represent the two largest euro zone economies. Further, the Netherlands and Austria are two smaller central European economies, of which Austria suffered from an almost steadily rising debt to GDP ratio over the observation period whereas the Netherlands were able to remarkably reduce their debt ratio in the 1990s. Italy and Portugal have been included because they both have been strongly affected by the 2008 financial and public debt crisis. In order to draw meaningful conclusions we also include the USA in our sample as one of the largest economies world wide. Other countries are neglected, as Japan, for example, is not comparable due to its special features, see for instance Fincke and Greiner (2011). Moreover, taking data until 2012 allows us to take into consideration the influence of the financial and public debt crisis that started in 2008.

Following the approach in Kumar and Woo (2010), we divide the whole observation period into sub-periods with non-overlapping intervals. As concerns growth, we distinguish three types of intervals (five years $q=5$, three years $q=3$ and one year $q=1$ ). This implies that we analyze the question of how the public debt to GDP ratio at time $t-q$ affects the growth rate for the following $q$ years. Consequently, for $q=5$ the seven intervals are (1970-1975), (19761981), .., (2000-2005) and (2006-2011), while for $q=3$ the eleven sub-periods start with (1970-1973) and end with (2010-2012), where the last interval comprises only two years. 
The following figures 1 and 2 show the GDP growth rates over an interval of three years $(q=$ 3 ), calculated as the difference of the natural logarithm of real GDP per capita, and the public debt to GDP ratio, measured at the beginning of the period ${ }^{3}$.

The figures have been plotted using scatterplot implemented in the package car in R. The lines represent a nonparametric regression smooth (see for instance Fox et al., 2013), whereas the dots and crosses etc. represent the actual observations. Obviously, there is a generally decreasing trend with respect to the GDP growth rate across all seven economies, while the debt to GDP ratio basically increases over time. Thus, our sample seems to represent rather a homogeneous set of economies. Certainly, both figures are significantly shaped by the financial and public debt crisis visible in the more recent time intervals. This graphical illustration suggests a negative relationship between public debt and economic growth.

To get a more profound idea about the relationship between public debt and economic growth, we first estimate the following pooled regression model, where we proceed as in Kumar and Woo (2010) and Dreger and Reimers (2013),

$$
y_{i, t}-y_{i, t-q}=\varphi_{0}+\psi b_{i, t-q}+\sum_{\mathrm{j}} \varphi_{j} C_{j, i, t-q}+\varepsilon_{i, t}
$$

with $y_{i, t}$ the natural logarithm of real GDP per capita for country $i$ at time $t$. Further, $b$ is the public debt to GDP ratio, $C$ gives the vector of the control variables and term. All regressors are measured at the beginning of a period, i.e. at $t-q$. This analyze the effect of the initial explanatory variable on economic growth in subsequent periods.

Concerning the control variables we include the initial real GDP per capita $\left(y_{i, t-q}\right)$ expressed in log units. It is added accounting for conditional convergence, meaning that economies with smaller capital stocks and lower income are characterized by higher growth rates on their way to the long-run balanced growth path. Also, foreign trade $\left(\operatorname{Trade}_{i, t-q}\right)$ is considered. It is proxied by the difference between exports and imports (i.e. the external trade balance or net exports) relative to GDP. This external trade balance is added to the regression since openness promotes the efficient allocation of resources and leads to the dissemination of technical progress, plus, it raises competition in markets and, thus, is favorable to growth (see e.g. Young, 1991, and in order to proxy the size of the government. It is calculated as government consumption expenditures relative to GDP. As a proxy for stabilization and potential differences in monetary policies in the sample the initial annual inflation rate $\left(\right.$ Infl $\left._{i, t-q}\right)$ is included. In order to check for robustness, the log of the population $\left(P_{o p} p_{i, t-q}\right)$ had initially been included, too, but it did not yield a significant effect or change the results essentially ${ }^{4}$. Summary statistics of each variable can be found in appendix B.

The data set contains variables for the seven selected economies Austria, France, Germany, Italy, the Netherlands, Portugal and the USA for the years from 1970 until 2012. The data are mainly taken from OECD (2013), such as the GDP, public debt, imports and exports and governmental consumption. For the population and for the GDP deflator statistics, we resorted to IMF (2013). Concerning Germany, the change in 1992 reflects the transition from Western Germany to reunified Germany. For Portugal, in order to get a long time series of public debt, the data have been merged into one series in 1996. This was due to data availability. Further, the Portuguese GDP deflator has been taken from OECD (2013) which has the base year 2006 instead of 2005 (as the IMF data). Since the data for EU economies were in part only available in national currencies, before the introduction of the Euro, they have been transformed to Euro

\footnotetext{
${ }^{3}$ The figures and the estimations have been performed using R 2.5.0., except when a newer version was necessary to implement a certain package.

${ }^{4}$ Cf. Fincke and Greiner (2015).
} 
according to the fixed exchange rates, e.g. for Germany $1 €=1.95583 \mathrm{DM}$ or for Portugal $1 €$ $=200.482$ Escudos. For the trade (openness) variable the net exports or external balance (difference of exports minus imports), on a national account basis, has been used. Originally, these series were measured in US \$. A transformation to Euro has been performed using an exchange rate of 1 US $\$=0.75 €$ (as of August 2013).

All growth rates have been computed as the difference of the natural logarithm of a variable $\mathrm{x}$ at the end of the period $(t)$ and the beginning of the period $(t-q)$, i.e. $\mathrm{gx}=\ln \left(x_{t}\right)-\ln \left(x_{t}-q\right)$.

Figure 1. Three-years growth rate.

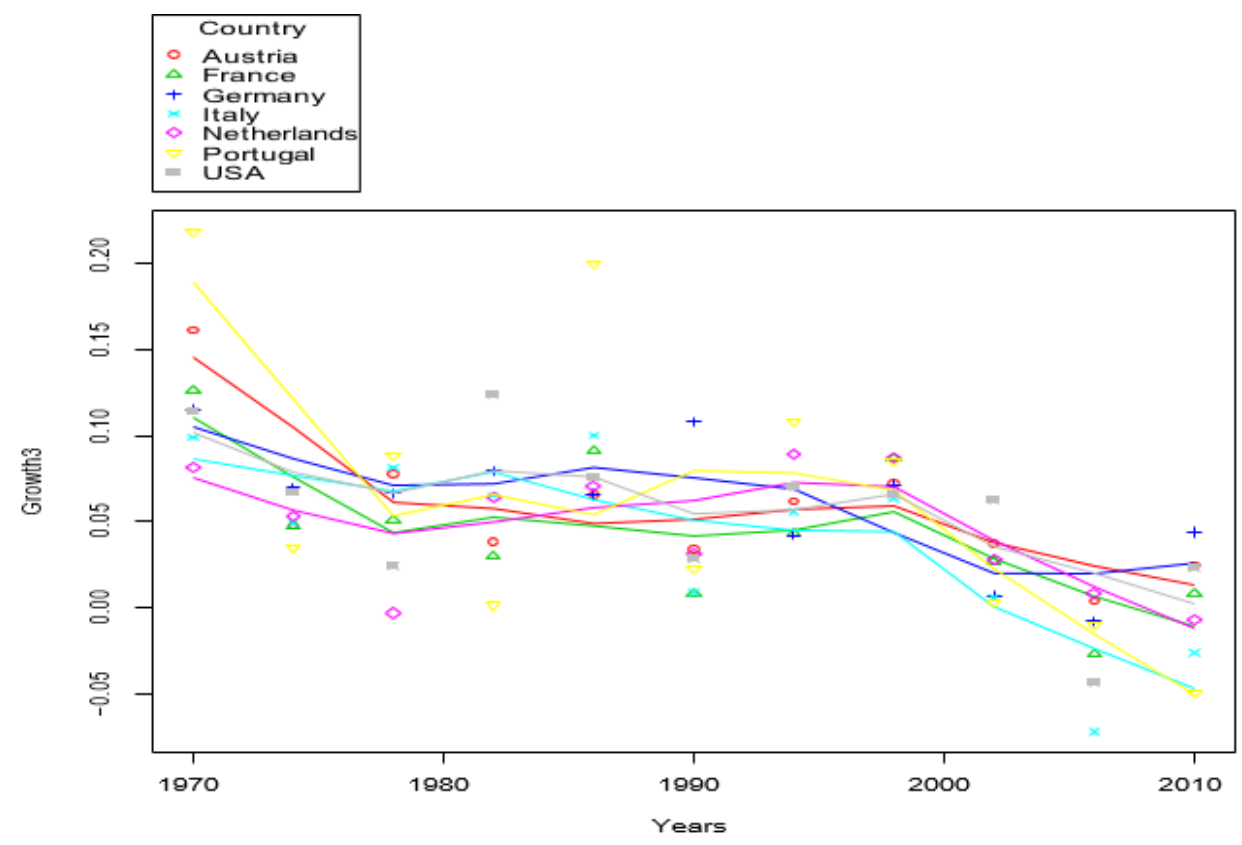

Data: OECD (2013) and IMF (2013), lines present a nonparametric regression smooth.

Figure 2. Public debt to GDP ratio.

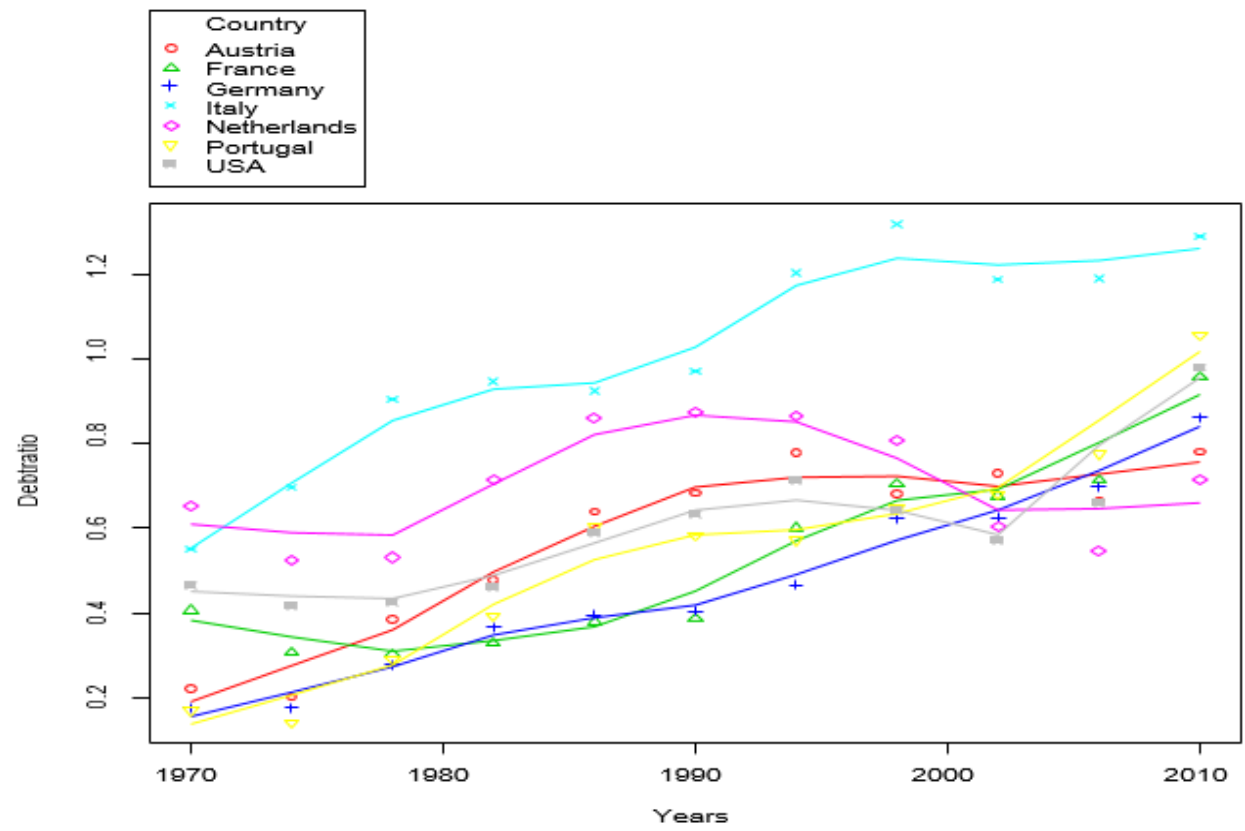

Data: OECD (2013) and IMF (2013), lines present a nonparametric regression smooth. 


\section{Estimation results}

Figures 1 and 2 in the last section suggest a negative relationship between economic growth and the public debt to GDP ratio. Neglecting for the moment all control variables, the relation between the public debt to GDP ratio and the subsequent economic growth rate for all seven economies can be estimated according to

$$
y_{i, t}-y_{i, t-q}=\varphi_{0}+\psi b_{i, t-q}+\varepsilon_{i, t}
$$

for which we use the R package plm (see for instance Croissant and Millo, 2008, or Kleiber and Zeileis, 2008. In general the $\mathrm{R}$ package plm estimates linear panel data models). Table 1 summarizes the results.

The results in table 1 are distinguished by type, i.e. pooled OLS regression (first block), a fixed effects model (second block) and a random effects model (third block). All estimation results indicate a statistically significant negative relationship between the public debt to GDP ratio and the subsequent economic growth. This also holds true for all three time period periods ( $q=5$ five-year growth, $q=3$ three-year growth and $q=1$ annual growth, respectively). Further, the estimation results suggest that the negative effect of the debt to GDP ratio is stronger for the five-year period than for the three-years interval and the three-year period effect is larger than the effect on the annual economic growth rate, which may be due to the fact that the first interval, $q=5(q=3)$, is much longer than the latter, $q=3(q=1)$. The Durbin Watson statistic, $D W$, suggests non-autocorrelated residuals for the five-years interval and for the three-years period, whereas there is a slight positive autocorrelation in the estimations with annual growth rates.

Table 1. Plain panel estimation results.

\begin{tabular}{|c|c|c|c|}
\hline \multicolumn{4}{|c|}{ Pooled model } \\
\hline & $q=5(N=49)$ & $q=3(N=77)$ & $q=1 \quad(N=294)$ \\
\hline Constant & $0.139 * * *$ & $0.100 * * *$ & $0.029 * * *$ \\
\hline$b_{t-q}$ & $-0.089 * *$ & $-0.076 * * *$ & $-0.018 * * *$ \\
\hline$R^{2}($ adj $)$ & 0.16 & 0.16 & 0.04 \\
\hline$D W$ & 1.72 & 2.26 & 1.62 \\
\hline \multicolumn{4}{|c|}{ Fixed effects model } \\
\hline & $q=5$ & $q=3$ & $q=1$ \\
\hline$b_{t-q}$ & $-0.132 * *$ & $-0.104 * * *$ & $-0.025 * * *$ \\
\hline$R^{2}(a d j)$ & 0.16 & 0.17 & 0.04 \\
\hline$D W$ & 1.96 & 2.40 & 1.65 \\
\hline F test & $\mathrm{F}=0.68, \mathrm{p}$-val. $=0.67$ & $\mathrm{~F}=0.66, \mathrm{p}-\mathrm{val} .=0.69$ & $\mathrm{~F}=0.75, \mathrm{p}$-val. $=0.61$ \\
\hline \multicolumn{4}{|c|}{ Random effects model } \\
\hline & $q=5$ & $q=3$ & $q=1$ \\
\hline Constant & $0.149 * * *$ & $0.107 * * *$ & $0.031 * * *$ \\
\hline$b_{t-q}$ & $-0.105 * *$ & $-0.087 * * *$ & $-0.020 * * *$ \\
\hline$R^{2}($ adj $)$ & 0.16 & 0.17 & 0.04 \\
\hline$D W$ & 1.80 & 2.31 & 1.63 \\
\hline Hausman test & $\chi^{2}=1.03$ p-val. $=0.31$ & $\chi^{2}=1.49$ p-val. $=0.22$ & $\chi^{2}=1.46$ p-val. $=0.23$ \\
\hline
\end{tabular}

Note: $* *(0.1 \%$ level $), * *(1 \%$ level $), *(5 \%$ level $), \bullet(10 \%$ level $)$. 
Despite the rather modest fit there is, nevertheless, some empirical evidence for a negative relationship between the two variables debt and growth. This result is also supported and visualized in the corresponding scatterplots with the linear regression line from the pooled OLS estimation in figure 3. Finally, the model selection tests (the F-test tests if the pooled or the fixed effects model is more appropriate and the Hausman test studies whether a random or fixed effects model should be applied) suggest the use of the pooled or the random model for this data set. However, all three estimations yield the same qualitative outcome anyway.

Next, we perform a non-parametric estimation for the plain model from above, i.e. including only the two variables debt and growth. Neglecting for the moment that the data come from different countries and treating the whole sample as one data set, allows us to study the (potentially) non-linear relationship between the two variables. Here, a spline estimation is applied to the data set, dealing with the relationship in a fairly unrestricted (non-parametric) manner.

Basically, it approximates the systematic link between the variables with a flexible function, here denoted by $s$, that is only required to be continuous and differentiable ${ }^{5}$.

$$
y_{t}-y_{t-q}=s\left(b_{t-q}\right)+\varepsilon_{t}
$$

The estimation is performed with the $m g c v$ package in R. Table 2 summarizes the estimation results identifying potential non-linearities. Non-linearities are indicated by the estimated degrees of freedom, $e d f$, where high values imply a wiggly function while a value near 1 suggests a linear fit. The second interesting part is the visualization of the estimation outcome. The plots of the estimated functions are shown in figure 4.

Figure 3. Pool, $q=5$ (left), $q=3$ (middle), $q=1$ (right).
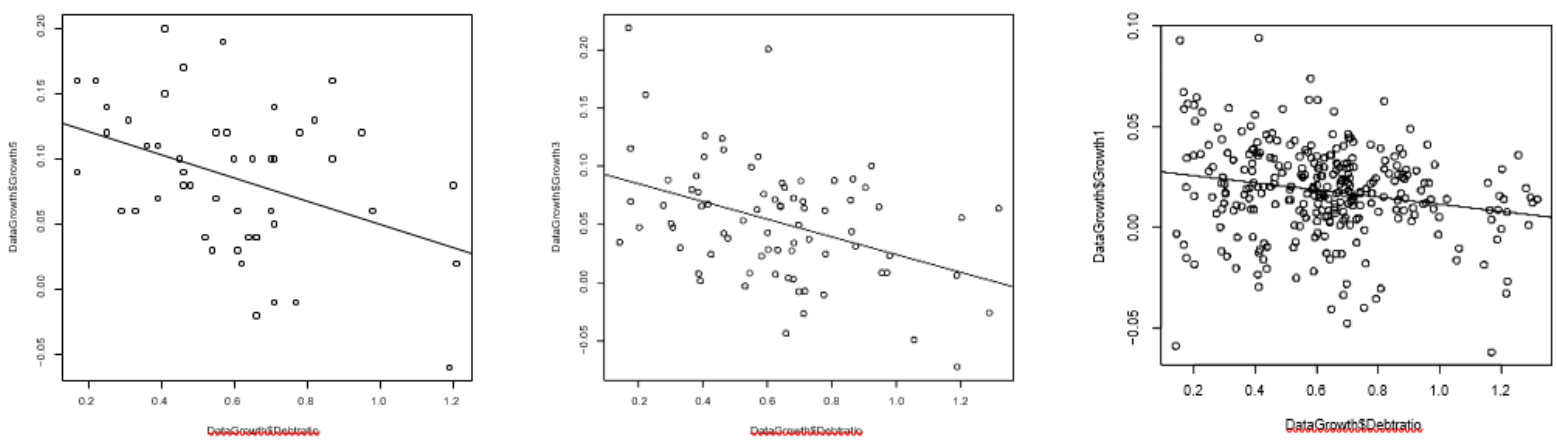

Figure 4. Spline, $q=5$ (left), $q=3$ (middle), $q=1$ (right).
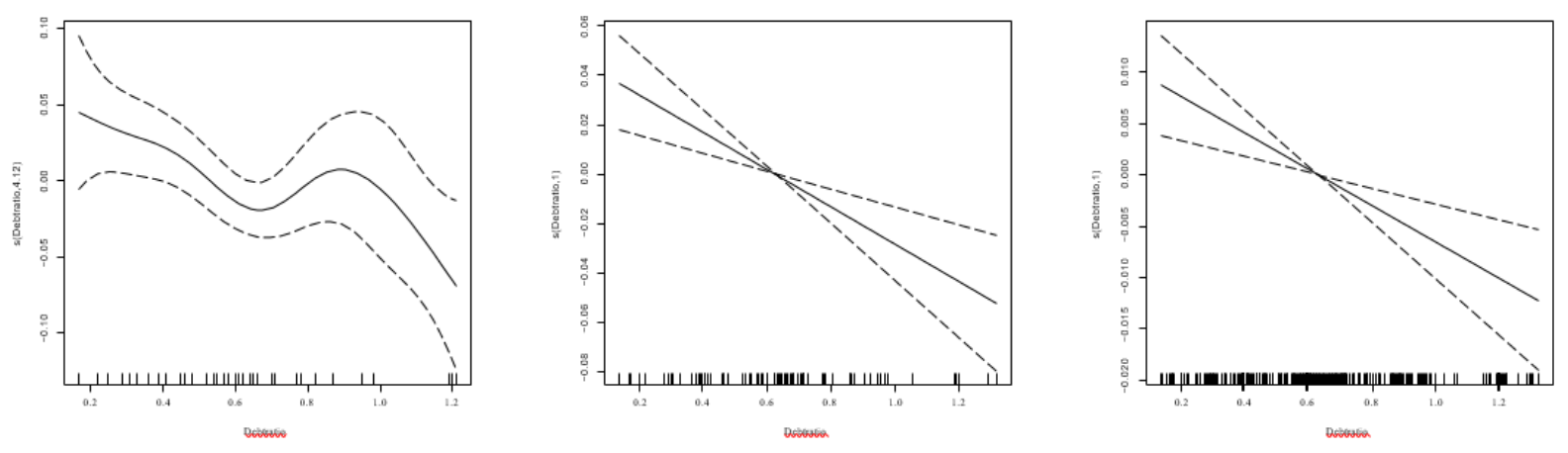

${ }^{5}$ For a short introduction to the method, see Kauermann (2006) or Greiner (2009) for instance. 
Table 2. Spline estimation results, plain model.

\begin{tabular}{|c|c|c|c|}
\hline \multicolumn{4}{|c|}{ Pooled model } \\
\hline & $q=5(N=49)$ & $q=3(N=77)$ & $q q=1 \quad(N=294)$ \\
\hline$e d f$ & $4.12^{*}$ & $1 * * *$ & $1 * * *$ \\
\hline$R^{2}($ adj $)$ & 0.21 & 0.15 & 0.04 \\
\hline$D W$ & 1.88 & 2.26 & 1.62 \\
\hline
\end{tabular}

Note: $* * *(0.1 \%$ level $), * *(1 \%$ level $), *(5 \%$ level $), \cdot(10 \%$ level $)$.

As table 2 and figure 4 shows, only for the five-years interval the relationship might be nonlinear. Basically, all three time periods are characterized by a negative relation, with a linear shape for the three-years growth rate and for the annual growth rate. The five-years interval also reveals a mainly negative form, however with a bump at a debt to GDP ratio of about $90 \%$. However, this is statistically significant only at the 5\% level. For the three-years interval and for annual growth the estimations do not show any evidence for non-linearities. Further, we also estimated an OLS regression including a quadratic term, $b^{2}{ }_{i t-q}$, and a cubic term, $b^{3}{ }_{i t-q}$, as regressors. None of these higher-order terms was statistically significant in the estimations, neither for the five-years interval, nor for the three-years or one-year time period ${ }^{6}$. Therefore, we conclude that the evidence for a non-linear relation between debt and growth is very weak in our sample.

From the outcomes in table 1 and figure 3 one can conclude that the relationship between the public debt to GDP ratio and the economic growth rate over the following year(s) is negative. However, for those plain estimations the only regressor was the debt to GDP ratio. In order to see how robust that result is, we next include the control variables in our estimations. Thus, the following regression equation is now estimated for the data of the seven selected economies:

$$
y_{i, t}-y_{i, t-q}=\varphi_{0}+\psi b_{i, t-q}+\varphi_{1} y_{i, t-q}+\varphi_{2} \text { Trade }_{i, t-q}+\varphi_{3} \text { GCons }_{i, t-q}+\varphi_{4} \text { Infl }_{i, t-q}+\varepsilon_{i, t}
$$

with the variables according to the explanations above. Table 3 presents the outcome.

As the results in table 3 demonstrate, the data suggest empirical evidence for a negative relationship between the public debt to GDP ratio and subsequent economic growth. Although the coefficient of interest for $b_{t-q}$ is not statistically significant for the five year growth interval (first column), the three-years period (second column) and the annual growth rates (last column) indicate a negative relationship between debt and growth. The estimation results also suggest, again, that the negative effect of the debt to GDP ratio is stronger for the three-years period than for the annual economic growth rate, which may be due to the fact that the first interval $(q=3)$ is much longer than the latter $(q=1)$. The other control variables show the expected signs. For instance, the negative coefficient of the initial real GDP per capita demonstrates that a higher initial GDP per capita reduces growth in subsequent periods, suggesting convergence. As above, this holds true for all three time specifications, i.e. for $q=5, q=3$ and $q=1$. Moreover, trade (openness), shown in the fourth line, has a positive effect on subsequent growth for all three estimations. The estimation also reveals that higher government consumption seems to lower economic growth in the following years, as does higher inflation in the initial year.

Since the fixed effects model did not yield significant results concerning the debt and growth relationship we, next, estimate the random effects model for our panel data. Table 4 presents the estimation results.

\footnotetext{
${ }^{6}$ The estimation results can be found in appendix A.
} 
Table 3. Panel estimation results, pooled OLS.

\begin{tabular}{crrr}
\hline \hline & $q=5(N=49)$ & $q=3(N=77)$ & $q=1(N=294)$ \\
\hline Constant & $0.853^{* *}$ & $0.921^{* * *}$ & $0.313^{* * *}$ \\
\hline$b_{t}-q$ & -0.051 & $-0.050^{*}$ & $-0.012^{*}$ \\
\hline$y_{t}-q$ & $-0.067^{*}$ & $-0.072^{* * *}$ & $-0.025^{* * *}$ \\
\hline Trade $_{-}-q$ & $0.193^{\circ}$ & $0.223^{* * *}$ & $0.086^{* * *}$ \\
\hline GConst $-q$ & -0.390 & $-0.560^{* *}$ & $-0.188^{* * *}$ \\
\hline Inft $-q$ & 0.029 & -0.194 & $-0.093^{* * *}$ \\
\hline$R^{2}(a d j)$ & 0.27 & 0.39 & 0.15 \\
\hline$D W$ & 1.78 & 2.02 & 1.73 \\
\hline \hline
\end{tabular}

Note: ***(0.1\% level), **(1\% level), *(5\% level), $\bullet(10 \%$ level $)$.

Table 4. Panel estimation results, random effects.

\begin{tabular}{crrr}
\hline \hline & $q=5(N=49)$ & $q=3(N=77)$ & $q=1(N=294)$ \\
\hline Constant & $1.388^{* * *}$ & $0.957^{* * *}$ & $0.324^{* * *}$ \\
\hline$b_{t}-q$ & 0.018 & $-0.049^{*}$ & $-0.011^{*}$ \\
\hline$y_{t}-q$ & $-0.125^{* * *}$ & $-0.075^{* * *}$ & $-0.026^{* * *}$ \\
\hline Trade $_{-}-q$ & 0.159 & $0.225^{* * *}$ & $0.087^{* * *}$ \\
\hline CCons $_{t}-q$ & -0.399 & $-0.582^{* *}$ & $-0.196^{* * *}$ \\
\hline Inf $_{t-q}$ & 0.022 & -0.206 & $-0.098^{* *}$ \\
\hline$R^{2}(a d j)$ & 0.36 & 0.41 & 0.17 \\
\hline$D W$ & 1.75 & 2.03 & 1.74 \\
\hline \hline
\end{tabular}

Note: $* * *(0.1 \%$ level $), * *(1 \%$ level $), *(5 \%$ level $), \bullet(10 \%$ level $)$.

Basically, the estimation of the random effects model confirms the results from the pooled OLS estimation of our model. The estimations suggest a significant negative relationship between the initial public debt to GDP ratio and the subsequent three-years or annual growth rate of GDP. Further, the coefficients are quite similar in size. The control variables show the expected signs and also support the results from the pooled model in table 3. Again, for both estimations, pooled and random effects, the hypothesis of non-autocorrelated residuals cannot be rejected, except for the one-year time interval.

Concerning model suitability, the F test suggests the pooled model for $q=5$ and the fixed effects model for $q=3$ and $q=1$. The Hausman test supports the suitability of the random effects model for the first two specifications. Especially for $q=3$, it yields a p-value of 0.9994 (see table 5). For $q=1$, the fixed effects model may be more appropriate. However, the estimated coefficient for the debt ratio in the fixed effects model is insignificant, which is contrary to the majority of the outcomes presented in this section.

Relating our results to earlier studies shows, that for advanced economies, there seems to be a negative relationship between debt and subsequent growth, as has also been found by Kumar and Woo (2010) for example. This relation may be different as regards developing and emerging market economies, as has been found for instance by Fincke and Greiner (2014), as they are on the transition path. Further studies merge different types of countries and perform dynamic panel threshold estimations, such an estimation may also be of interest for our set of economies for future studies in order to elaborate further on the non-linearities of the relationship. 
Table 5. Model selection tests.

\begin{tabular}{crrr}
\hline \hline & $q=5$ & $q=3$ & $q=1$ \\
\hline \multirow{2}{*}{ F test } & $\mathrm{F}=1.92$ & $\mathrm{~F}=3.85$ & $\mathrm{~F}=3.60$ \\
\cline { 2 - 4 } & $\mathrm{p}-\mathrm{val} .=0.104$ & $\mathrm{p}$-val. $=0.002$ & $\mathrm{p}$-val.=0.002 \\
\hline \multirow{2}{*}{ Hausman test } & $\chi^{2}=3.86$ & $\chi^{2}=0.17$ & $\chi^{2}=21.08$ \\
\cline { 2 - 4 } & $\mathrm{p}$-val. $=0.57$ & $\mathrm{p}$-val. $=0.999$ & $\mathrm{p}$-val. $=0.0008$ \\
\hline \hline
\end{tabular}

\section{Conclusions}

In this paper we have empirically analyzed the relationship between public debt and economic growth. Our regression results yield empirical evidence for a negative relationship between the public debt to GDP ratio and the growth rate of the economies in subsequent periods. This means that a high public debt to GDP ratio at the beginning of the period tends to reduce the real GDP per capita growth rate in the following years.

We performed panel data estimations where we estimated several regression models. When the control variables are neglected, all models yield a significant negative relation between the public debt to GDP ratio and economic growth in the subsequent period for the five-years time interval, for the three-years time interval and for the annual interval. When control variables are included in the regression, this statistically significant negative correlation between debt and growth is still present for the pooled and the random effects model for the three-years time interval and for the one-year time interval, whereas the effect of public debt becomes statistically insignificant for the five-years interval. Further, the link between debt and growth seems to be characterized by a linear relationship since the empirical evidence for non-linearities is very weak. In particular, we could not find any indication of non-linearities for the three-years time interval and for annual growth rates.

Hence one policy implication we can draw from our study is that economies should reduce their public debt to GDP ratios in order to spur growth. However, that does not mean that governments necessarily have to run balanced budgets. Slight deficits that imply that public debt grows but less than GDP also leads to a reduction of the debt to GDP ratio and, thus, may spur growth. However, care should be taken when reducing public spending and it should be kept in mind that, from a growth perspective, cuts in productive public spending for infrastructure or for human capital formation may turn out to be counterproductive.

With respect to future research, it would be interesting to study the robustness of the outcome. In this paper we have analyzed advanced industrial economies. But, for emerging market economies the relation may be different. For example, in Fincke and Greiner (2014) a positive correlation between public debt and economic growth has been detected, suggesting that the relation between debt and growth in emerging market economies may be different from that in industrialized countries. One explanation for that difference could be that this relation is different in fast growing economies on the transition path from that in industrialized countries that can be characterized by a steady state growth path. To get more insight into this question further research is needed that applies more advanced techniques, such as estimating a dynamic panel threshold model for example.

Acknowledgements. We thank two referees for valuable comments on an earlier version that helped to improve the paper. 


\section{References}

Ballasone, F., Francese M. and Pace A. (2011) "ublic Debt and Economic Growth in Italy. Quaderni di Storia Economica / Economic History Working Papers, n. 11, October 2011, Banca d'Italia, Rome.

Caner, M., Grennes, T. and Koehler-Geib F. (2010) Finding the tipping point - When sovereign debt turns bad, The World Bank, Policy Research, Working Paper 5391.

Checherita, C. and Rother, P. (2010) The impact of high and growing debt on economic growth. An empirical investigation for the euro area. ECB working paper, series number 1237.

Checherita-Westphal, C., Hallett, A.H. and Rother, P. (2012) Fiscal sustainability using growth-maximising debt targets, ECB working paper, series number 1472.

Croissant, Y. and G. Millo (2008) Panel Data Econometrics in R: The plm Package, Journal of Statistical Software Volume, 27 (2).

Dreger, C. and Reimers, H.E. (2013) Does Euro Area Membership Affect the Relation between GDP Growth and Public Debt?, Journal of Macroeconomics, DIW Discussion Paper 1249, 2012.

Egert, B. (2015) Public Debt, Economic Growth and Nonlinear Effects: Myth or Reality?, Journal of Macroeconomics, 43, 226-238.

Ferreira, C. (2009) Public Debt and Economic Growth: a Granger Causality Panel Data Approach, School of Economics and Management, Technical University of Lisbon, working paper 24/2009.

Fincke, B. and Greiner, A. (2011) Do large industrialized economies pursue sustainable debt policies? A comparative study for Japan, Germany and the United States, Japan and the World Economy, 23, 202-13.

Fincke, B. and Greiner, A. (2014) Public debt and economic growth in emerging market economies, forthcoming in: South African Journal of Economics.

Fox, C., Weisberg, S., Adler, D., Bates, D., Baud-Bovy, G., Ellison, S., Firth, D., Friendly, M., Gorjanc, G., Graves, S., Heiberger, R., Laboissiere, R.. Monette, G., Murdoch, D., Nilsson, H., Ogle, D., Ripley, B., Venables, W., and Zeileis, A. (2013), Package car, available at: http://cran.r.project.org/web/packages/car/car.pdf (accessed 6 November 2013).

Greiner, A. (2009) Estimating penalized spline regressions: theory and application to economics, Applied Economics Letters, 16, 1831-1835.

Greiner, A. (2013) Debt and growth: Is there a non-monotonic relation?, Economics Bulletin, 33, 340-47.

Grossman, G. and Helpman, E. (1991) Innovation and Growth in the Global Economy. MIT Press, Cambridge, Mass.

IMF (2013) International Financial Statistics, via StatistikNetz.de, DSI Data Service and Information.

Kauermann, G. (2006) Nonparametric models and their estimation, Allgemeines Statistisches Archiv, 90, 137-152.

Kleiber, C. and Zeileis, A., (2008) Applied Econometrics with R. Use R!, Springer, New York.

Kumar, M.S. and Woo, J. (2010) Public debt and growth, IMF working paper number $\mathrm{WP} / 10 / 174$.

OECD Databases (2013) Economic Outlook Statistics and Projections, also Fiscal Positions and Business Cylcles (historical ed.), via StatistikNetz.de, DSI Data Service and Information.

Panizza, U. and Presbitero, A.F. (2013) Public debt and economic growth in advanced economies: A Survey, Swiss Journal of Economics and Statistics, 149, 175-204. 
Reinhart, C.M. and Rogoff, K.S. (2010) Growth in a time of debt, NBER working paper number 15639.

Smyth, D.J. and Hsing, Y. (1995) In search of an optimal debt ratio for economic growth, Contemporary Economic Policy, 13, 51-59.

Young, A. (1991) Learning by Doing and the Dynamic Effects of International Trade, Quarterly Journal of Economics, 106, 369-405. 


\section{Appendix A}

\section{Additional estimation results}

The estimation results for the plain estimations including the quadratic and cubic term for the five-years $q=5$, the three years $q=3$ and the annual $q=1$ interval are given as follows:






\section{Appendix B}

\section{Summary statistics}

This section provides additional information on the data set. Table 6 shows the central information as regards the summary statistics (comprising each variable across time and countries). The mean of the growth rates and the inflation (as it presents growth of prices) are calculated referring to the geometric mean.

Table 6. Detailed data information (own calculations).

\begin{tabular}{lccccc}
\hline \hline Variable & No. of obs. & \multicolumn{4}{c}{$\begin{array}{c}\text { Descriptibe statistics } \\
\text { Mean Min Max StD }\end{array}$} \\
\hline \hline Growth $q=5$ (in \%) & 49 & 0.09 & -0.06 & 0.20 & 0.06 \\
\hline Growth $q=3$ (in \%) & 77 & 0.05 & -0.07 & 0.22 & 0.05 \\
\hline Growth $q=1$ (in \%) & 249 & 0.02 & -0.06 & 0.09 & 0.02 \\
\hline \hline Public debt to GDP & 294 & 0.63 & 0.14 & 1.32 & 0.26 \\
\hline Initial GDP p.c. $($ ln) & 294 & 9.93 & 8.70 & 10.68 & 0.39 \\
\hline Trade balance to GDP & 294 & -0.02 & -0.73 & 0.09 & 0.09 \\
\hline Gov. consumption to GDP & 294 & 0.19 & 0.11 & 0.29 & 0.03 \\
\hline Inflation (in \%) & 294 & 0.05 & -0.02 & 0.23 & 0.05 \\
\hline \hline
\end{tabular}

